\title{
POLÍTICAS PÚBLICAS: UM ESTUDO BÁSICO E CONCEITUAL DO FIES
}

\section{PUBLIC POLICIES: A BASIC AND CONCEITUAL STUDY OF FIES}

Ary Manoel Gama da Silva* Rogerio da Silva Rocha**

\begin{abstract}
Resumo: $O$ presente trabalho pretende fazer uma abordagem sobre as políticas públicas educacionais Programa Universidade Para Todos - Prouni e o Fundo de Financiamento ao Estudante do Ensino Superior - FIES, que se mostram como mecanismos de democratização do acesso ao ensino superior. Assim com o objetivo de estudar de forma básica e conceitual o Fundo de Financiamento Estudantil - FIES, esse artigo foi elaborado através de pesquisa teórica, analisando o FIES e outras políticas públicas de financiamento educacional, como o Programa Universidade para Todos - PROUNI. O conteúdo disposto no artigo gera ainda uma reflexão sobre as políticas educacionais brasileiras que se mostram como instrumentos de acesso ao ensino superior e promovem a inserção de uma população economicamente menos favorecida a níveis mais elevados na camada socioeconômica.
\end{abstract}

Palavras-chave: FIES. PROUNI. Ensino. Políticas. Superior.

Abstract: This work intends to make an approach on educational policies University for All Program - Prouni Fund and Student Financing of Higher Education - Fies, which show how mechanisms of democratization of access to higher education. In order to study in a basic and conceptual way the Financing Fund the Higher Education Student (FIES), this essay was written based on theoretical research, analyzing FIES and other educational public policies, as the University for All Program (PROUNI). The content of the article generates a reflection on the Brazilian educational policies which are instruments of access to higher education and promote the inclusion of socioeconomically disadvantaged population into higher socioeconomic levels.

Keywords: FIES. PROUNI. Education. Policies. Superior.

\footnotetext{
* Mestrando pelo Programa de Pós Graduação e Desenvolvimento Local pelo Centro Universitário Augusto Motta. Especialista em Administração da Qualidade pela Universidade Cândido Mendes. Graduado em Tecnologia de Redes Avançadas de Telecomunicações pela Universidade Estácio de Sá. Professor na Universidade Estácio de Sá.

** Mestrando em Desenvolvimento Local no Programa de Mestrado Profissional em Desenvolvimento Local pela UNISUAM. Pós Graduado em Docência do Ensino Superior pela UniverCidade. Graduado em Economia pela Universidade Federal Rural do Rio de Janeiro.
} 


\section{INTRODUÇÃO}

\subsection{Conceito De Políticas Públicas}

Antes de definir-se política pública, há uma questão que deve ser esclarecida: a política não é uma norma nem um ato jurídico; no entanto, as normas e atos jurídicos são componentes da mesma, uma vez que esta pode ser entendida como um conjunto organizado de normas e atos tendentes à realização de um objetivo determinado.

As normas, decisões e atos que integram a política pública têm na finalidade da política seus parâmetros de unidade. Isoladamente, as decisões ou normas que a compõem são de natureza heterogênea e submetem-se a um regime jurídico próprio.

\subsection{Conceito, Características e Tipos de Políticas Públicas}

Traçar um conceito de política pública exige antes de tudo entender o significado da palavra "política". Segundo Bobbio (2000, p. 159) a palavra política encontra-se associada a tudo o que se relaciona à cidade, civil, sociável ou social.

Para Bucci (2002, p. 269) o adjetivo "pública", justaposto ao substantivo "política", sinaliza tanto os destinatários como também os autores da política. É de fato que uma política será pública quando efetivamente contemplar interesses públicos, ou seja, voltados à coletividade. Não que isso seja uma mera fórmula justificadora, mas sim por ser sua realização desejada pela sociedade. Sendo assim, fica alertado que uma política pública também deve ser expressão de um processo público, no sentido da possibilidade de participação de todos os interessados, diretos e indiretos, permitindo manifestação clara e transparente dos interesses respectivos.

Desse modo, é possível afirmar que a política pública traz consigo, como pressuposto, a participação dos cidadãos na tomada de decisões acerca de projetos e atividades que irão influenciar diretamente as suas vidas.

Segundo Bontempo (2005, p. 210) as políticas públicas estão diretamente ligadas à implementação dos direitos sociais, enfatizando que o Estado deve ter uma postura ativa para garantir a constitucionalização de tais direitos sociais, com a 
finalidade de promover condições para que eles possam ser efetivamente usufruídos e, segundo a autora, estas condições, que devem ser produzidas pelo Estado, nada mais são do que as chamadas "políticas públicas".

Importante referir que a visão de política pública está ligada à concepção de Estado que se adota, ou seja, o ideário do modelo de Estado é que irá determinar a política pública a ser adotada.

Nesse sentido Bucci (2002, p. 244-245) diz:

Uma primeira dificuldade em se trabalhar com a noção de política pública em direito diz respeito à relação entre o direito e o modelo de Estado. Pois, se se concebe a política pública como criação do Estado de bem-estar, expressa sempre como forma de intervenção do Estado, e se adota como premissa a exaustão do Estado de bemestar - o que é uma constatação não apenas de autores neoliberais seria, discutível definir o Estado contemporâneo como "fundamentalmente, Estado implementador de políticas públicas". Teria sentido falar em Estado implementador de políticas públicas no caso da era do Estado de bem-estar?

No mesmo sentido é a lição de Azevedo (2001), ao afirmar que as políticas públicas, do mesmo modo que qualquer ação humana, são definidas, implementadas, reformuladas ou desativadas com base na memória da sociedade ou do Estado. Afirma que tais políticas são formuladas a partir das representações sociais que cada sociedade desenvolve a respeito de si própria, assim, são ações que guardam intrínseca vinculação com o universo cultural e simbólico, que é próprio de uma determinada realidade social.

Cada vez mais os estudiosos do direito têm se interessado por essa questão, segundo Bucci (2001, p. 5):

Definir como campo de estudo jurídico o das políticas públicas é um movimento que faz parte da onda, relativamente recente, de interdisciplinaridade no direito. Alguns institutos e categorias tradicionais do direito hoje rarefeitos buscam novo sentido ou nova força restabelecendo contato com outras áreas do conhecimento, das quais vinha se apartando desde a caminhada positivista que se iniciou no século XIX. Ter-se firmado como campo autônomo, dotado de "objetividade" e "cientificidade" - desafios do positivismo jurídico - é hoje um objetivo até certo ponto superado. 
No Brasil é recente a preocupação com implantação de políticas públicas. Um produto do processo do estabelecimento de uma nova organização política do Estado, fundamentada na descentralização, passando o Município a ser reconhecido pela Constituição de 1988 ao lado da União, como um dos membros da Federação, como os Estados e Distrito Federal.

As políticas públicas têm, em cada Estado, o respaldo legal da Constituição Federal, da Constituição Estadual e Lei Orgânica do Município. Podem ser definidas como o conjunto de programas de ação governamental voltados à concretização de direitos sociais. Caracterizam-se como um instrumento de planejamento, racionalização e participação popular.

Para Bucci (2001) a necessidade do estudo das políticas públicas está diretamente ligada com a busca da concretização dos direitos humanos, em particular os direitos sociais. Feitas estas observações, quanto ao conceito de políticas públicas é possível defini-las como sendo: "programas de ação governamental voltados à concretização de direitos".

Tais direitos abrangem os direitos fundamentais, inclusive os estabelecidos em pactos internacionais, depois ratificados e internados nas ordens jurídicas nacionais, assim, tal entendimento vem sendo ampliado, a ponto de abranger hoje o direito síntese do desenvolvimento. Para essa definição, mesmo as políticas públicas relacionadas apenas medianamente com a concretização de direitos, tais como a política industrial, a política energética etc., também carregam um componente finalístico, que é assegurar a plenitude do gozo da esfera de liberdade a todos e a cada um dos integrantes do povo (BUCCI, 2001).

Assim, políticas públicas são o conjunto de ações políticas voltadas ao atendimento de demandas sociais, sendo sempre uma resposta às demandas apresentadas por atores políticos e sociais, como instituições, organizações, grupo de interesses ou lideranças.

Azevedo (2003, p. 38) leciona que "política pública é tudo o que um governo faz e deixa de fazer, com todos os impactos de suas ações e de suas omissões"

Segundo Heringer (2002, p. 85) política pública "se refere a princípios de ação de determinado governo, orientado para atingir fins e população específicos, ou seja, é um meio para se atingir determinada meta econômica ou social". 
Boneti (2006, p. 74) ao estabelecer uma definição de políticas públicas leciona:

[...] é possível compreender como políticas públicas as ações que nascem do contexto social, mas que passam pela esfera estatal como uma decisão de intervenção pública numa realidade social, quer seja para fazer investimentos ou para uma mera regulação administrativa. Entende-se por políticas públicas o resultado da dinâmica do jogo de forças que se estabelece no âmbito das relações de poder, relações essas constituídas pelos grupos econômicos e políticos, classes sociais e demais organizações da sociedade civil. Tais relações determinam um conjunto de ações atribuídas à instituição estatal, que provocam o direcionamento (e/ou o redirecionamento) dos rumos de ações de intervenção administrativa do Estado na realidade social e/ou de investimentos.

As políticas públicas acabam por apresentar-se como uma forma de Estado socialmente forte, na medida em que sua preocupação reside na efetivação de direitos sociais que até 0 momento apenas estão formalmente previstos, promovendo uma nítida substituição do governo das leis pelo governo das políticas públicas, nas palavras de Bucci (2002, p. 252):

As políticas públicas são instrumentos de ação dos governos - o government by policies que desenvolve e aprimora o government by law. A função de governar - o uso do poder coativo do Estado a serviço da coesão social - é o núcleo da idéia de política pública, redirecionando o eixo de organização do governo da lei para as políticas. As políticas são uma evolução em relação à idéia de lei em sentido formal, assim como esta foi uma evolução em relação ao government by men, anterior ao constitucionalismo. E é por isso que se entende que o aspecto funcional inovador de qualquer modelo de estruturação do poder político caberá justamente às políticas públicas.

Assim, se as políticas públicas têm por fim orientar a atuação governamental para um objetivo constitucionalmente previsto devem estar dirigidas ao cumprimento das tarefas correspondentes à concretização de direitos sociais, como é o caso do direito à educação.

Nesse sentido, as políticas públicas deverão buscar sempre a implementação dos direitos sociais, de sorte que a própria oportunidade e conveniência deverá ser perquirida tomando-se como referencial a ordem social. 
Segundo Azevedo (2003, p. 38) as políticas públicas têm duas características gerais, são elas: a busca do consenso em torno do que se pretende fazer ou deixar de fazer, sendo que, quanto maior for o consenso, mais facilmente as políticas propostas serão implementadas; e a definição de normas e o processamento de conflitos, podendo ser tanto para a ação como para a resolução dos conflitos entre os indivíduos e agentes sociais.

Tais características se aplicam a todas políticas públicas, que são classificadas em três tipos, segundo Azevedo (2003, p. 38), são elas: redistributivas, distributivas e regulatórias. As políticas públicas redistributivas, como o próprio nome já diz, têm como objetivo redistribuir renda na forma de recursos e/ou de financiamento de equipamentos e serviços públicos. Quanto às políticas distributivas são as que possuem objetivos pontuais ou setoriais ligados à oferta de equipamentos ou serviços públicos. São financiadas pela sociedade como um todo através do orçamento público e os beneficiários são pequenos grupos ou indivíduos de diferentes estratos de baixa renda. Já a política regulatória como o próprio nome já diz, têm como objetivo regular determinado setor, isto é, criar normas com o objetivo de fazer funcionar serviços e implementar equipamentos urbanos. Assim, segundo Azevedo (2003, p. 38), "a política regulatória se refere à legislação e é um instrumento que permite regular (normatizar) a aplicação de políticas redistributivas e distributivas $[\ldots]^{\prime \prime}$.

Assim sendo, as políticas públicas são programas de ação governamental visando a coordenar os meios à disposição do Estado e as atividades privadas, para a realização de objetivos socialmente relevantes e politicamente determinados.

As políticas públicas constituem uma temática oriunda da ciência política, e seu estudo está relacionado com a preocupação do Estado em concretizar ações que contemplem os direitos humanos, em particular os direitos sociais e, consequentemente, o direito a educação.

\section{POLÍTICAS PÚBLICAS NA EDUCAÇÃO BRASILEIRA}

A função social do Estado é garantir aos indivíduos o acesso aos seus direitos fundamentais, dentre eles o direito a educação. Tal função é desenvolvida através da 
implementação de políticas públicas em todas as áreas, destacam-se aqui as políticas públicas educacionais de acesso ao ensino superior, especificamente o Programa Universidade para Todos - Prouni e o Fundo de Financiamento ao Estudante do Ensino Superior - FIES, destinadas a possibilitar as pessoas de baixa renda acesso as instituições de ensino superior privadas.

Um estudo sobre as políticas públicas educacionais no ensino superior, com o intuito de verificar sua forma de atuação, possibilita detectar se as ações desenvolvidas pelo Estado estão atendendo ao seu objetivo, ou seja, se tais políticas educacionais de fato democratizaram o acesso ao ensino superior na medida em que garantem aos cidadãos o direito fundamental à educação.

\subsection{Fies e Prouni}

Instituído inicialmente pela Medida Provisória (MP) no 1.827, de 27 de maio de 1999, posteriormente convertida na Lei no 10.260, de 12 de julho de 2001, o Fundo de Financiamento Estudantil (FIES) sucedeu ao Programa de Crédito Educativo para Estudantes Carentes (CREDUC) de 1992, originado do Programa de Crédito Educativo (PCE) de 1975.

O FIES tem natureza contábil e foi criado com o objetivo de conceder financiamento a estudantes regularmente matriculados em cursos superiores não gratuitos, com avaliação positiva nos processos conduzidos pelo MEC e ofertados por instituição de educação superior privado aderente ao Fundo.

O programa está inserido no Plano Nacional de Educação (PNE), documento resultado de deliberação do Congresso Nacional e de discussão prévia nas Conferências Municipais, Estaduais e Nacional de Educação, com o objetivo de melhorar os índices educacionais do país em todos os níveis de educação. Desde sua criação em 1999, o FIES atendeu aproximadamente a 3,12 milhões de estudantes.

A partir de 2010, foram estabelecidas novas regras a fim de fomentar a demanda crescente por ensino superior dos estudantes de baixa renda. As inscrições passaram a ser realizadas em fluxo contínuo, durante todo o ano, tendo havido dilatação do prazo de carência de seis para dezoito meses e alongamento do período 
para a quitação do financiamento para três vezes o período financiado acrescido de mais doze meses.

Na sequência das alterações sofridas pelo programa, em 2010, foi criado pela Lei no 12.087 , 11 de novembro de 2009, com a redação dada pela Medida Provisória no 501, de 8 de setembro de 2010, um fundo de natureza privada com a finalidade de garantir parte do risco em operações de crédito educativo no âmbito do Fies, o Fundo de Garantia de Operações de Crédito Educativo (FGEDUC), uma modalidade de garantia estendida aos contratos dos estudantes matriculados em cursos de licenciatura, beneficiários de bolsas parciais do Prouni ou de baixa renda (renda familiar mensal bruta per capita de até 1,5 salário mínimo), prescindindo esses estudantes da obrigatoriedade de apresentar fiador em seus contratos.

O FGEDUC foi criado com o objetivo substituir o fiador convencional exigido nos financiamentos a estudantes com dificuldade de consegui-los, considerando o perfil de renda que apresentam, conforme já mencionado, e tem a União como cotista única.

Nesse contexto, apesar de constituir uma ação que objetiva contribuir para o cumprimento da Meta no 12 do PNE 2014-2024 (elevar a taxa bruta de matrícula na Educação Superior para 50\% e a taxa líquida para 33\% da população de 18 a 24 anos, assegurada a qualidade da oferta), o FIES, como relatado no presente Relatório de Gestão e demonstrado por recentes documentos do Tribunal de Contas da União, não veio sendo plenamente eficaz nesse objetivo (BRASIL, 2017a).

Em 2014, sobrevieram novas regras por força da adesão das entidades mantenedoras ao FIES e ao FGEDUC. Os contratos formalizados a partir de $1^{\circ}$ de fevereiro de 2014, garantidos por fiança convencional ou solidária, têm como garantia colateral o FGEDUC, de modo que em caso de inadimplemento das parcelas do financiamento, os fiadores e o Fundo Garantidor passaram a ser chamados a honrar a dívida inadimplida, valendo ressaltar que a garantia do FGEDUC, nestes casos, condiciona-se à disponibilidade de saldo deste Fundo, a qual é verificada a cada contratação inicial e renovação semestral, o que indica claramente que poderão ocorrer semestres (e respectivo saldo devedor) garantidos, concomitantemente, pelo FGEDUC e pela Fiança, enquanto outros semestres serão garantidos somente por Fiança Convencional. 
O programa passou por significativas mudanças, vindo a dispor de condições financeiras mais benéficas para o estudante que permitiram um crescimento em ritmo incompatível com a disponibilidade de recursos orçamentários no médio e longo prazo, tendo sido verificada, consequentemente, a transferência de parcela relevante dos riscos de financiamento ao setor público. Nesse contexto, as matrículas FIES passaram de aproximadamente 5\% do total efetuado na rede privada em 2009 para 39\% em 2015.

Até 2015, o FIES experimentou um expressivo aumento no número de contratos, que passou de pouco menos de 76 mil em 2010 para 2,18 milhões em 2015 , com recursos da ordem de $\mathrm{R} \$ 16,58$ bilhões. Diante deste cenário, decorreu a necessidade de ajustes deste Fundo ao contexto orçamentário do país e, a partir deste ano, passou por aprimoramentos objetivando melhor distribuição dos recursos públicos que o compõem, tendo sofrido reformulações e passado a contar, desde o segundo semestre de 2015, novamente com processo seletivo dotado de critérios estrategicamente estabelecidos para distribuição das vagas disponíveis ao financiamento.

Dentre tais critérios, destaca-se a priorização de cursos com melhores indicadores pelo Sistema Nacional de Avaliação da Educação Superior (Sinaes), distribuição por localização geográfica, identificando-se a demanda por financiamento estudantil e as condições socioeconômicas de cada microrregião onde há oferta, bem como áreas prioritárias (Engenharias e Ciência da Computação, Licenciaturas e Área da Saúde). Eis que, de fato, até o primeiro semestre de 2015, $60 \%$ (sessenta por cento) dos contratos de financiamento se encontravam nas regiões Sul, Sudeste e no Distrito Federal.

Assim, a partir de 2016, o critério de relevância social passou a ser apurado por microrregião com base na demanda por educação superior que corresponde ao número de estudantes participantes das edições do Exame Nacional do Ensino Médio (Enem) de 2014 e de 2015 e na demanda por financiamento estudantil, obtido a partir do número de estudantes inscritos no Fies no ano de 2015, com atribuição de peso de acordo com o Índice de Desenvolvimento Humano Municipal (IDHM) de cada microrregião, calculado a partir da média dos IDHs dos municípios que a compõem. 
Desta forma, com instituição do processo seletivo no segundo semestre de 2015, verificou-se definição no quantitativo da oferta de vagas, tendo sido disponibilizadas em 2017 aproximadamente 230.364 novas vagas, das quais 175.946 foram ocupadas, ou seja, uma taxa de ocupação de $76 \%$, bem como foi efetuada a renovação de aproximadamente 1,1 milhão de contratos de financiamento por semestre, dos 1,5 milhão vigentes no exercício em questão.

Ainda em 2016, no escopo de melhor qualificar o programa, a Lei no 13.366 , de $1^{0}$ de dezembro de 2016, mitigando os riscos e buscando garantir a sustentabilidade do Fundo, atribuiu às instituições de ensino responsabilidade parcial pela remuneração dos agentes operadores do Fundo, e incluiu como possibilidade de sanção às instituições, multa. Ainda, previu em texto legal a possibilidade de estabelecimento de valores máximo e mínimos de financiamento por meio de regulamento, possibilitou a prática de valores de encargos educacionais diferenciados a menor em favor do estudante financiado, e qualificou a questão do combate à inadimplência com a previsão de novas ferramentas, dentre outras melhorias (BRASIL, 2016a).

A Lei no 10.260, de 12 de julho de 2001, vem sendo objeto de alterações legislativas por diversas regulamentações, dentre as quais destaca-se a Lei $n^{0}$ 12.202, de 14 de janeiro de 2010, que outorgou ao Fundo Nacional de Desenvolvimento da Educação (FNDE) o encargo de agente operador do FIES (BRASIL, 2010), a Lei no 13.366, de $1^{\circ}$ de dezembro de 2016, que, dentre outras alterações, atribuiu às instituições de ensino responsabilidade parcial pela remuneração dos agentes operadores do Fundo (BRASIL, 2016a).

Mais recentemente, por meio da Medida Provisória no 785, de 6 de julho de 2017, convertida na Lei no 13.530, de 7 de dezembro de 2017, o programa foi reestruturado, adequando-o à realidade orçamentária do país, com vistas a garantir maior sustentabilidade ao Fundo, criando nova sistemática de oferta e de amortização do financiamento (BRASIL, 2017b), possibilitando pagamento atrelado à renda, e inserção de nova modalidade denominada Programa de Financiamento Estudantil, colaborando para o incremento da oferta de oportunidades de financiamento. 
Com o objetivo de aperfeiçoar a gestão do FIES, foi criado por meio do Decreto s/n, de 19 de setembro de 2017, o comitê gestor interministerial, alterando o quadro de gestão do FIES, o Comitê Gestor do Fundo de Financiamento Estudantil - CG-Fies, que tem como competência a definição as diretrizes e prioridades da política de financiamento estudantil para o Fies, em consonância com as metas do Plano Nacional de Educação - PNE, os requisitos de concessão, as condições técnicas e operacionais e a aprovação do Plano Trienal do Fies e seus ajustes anuais, considerando os impactos orçamentários e financeiros ao longo do tempo - o que fortalece o planejamento e a governança do Fies, ao tornar colegiadas as decisões, o acompanhamento e a avaliação dos resultados do programa, trazendo conhecimentos e capacidades diversos para a tomada de decisão.

Com a reformulação do quadro de gestão do FIES, foi transferida novamente à Caixa Econômica Federal (CAIXA) sua operacionalização e criada uma nova modalidade de financiamento, disponibilizada aos agentes financeiros privados, estendendo a possibilidade de estudantes entre 3 e 5 salários mínimos de renda familiar per capita bruta mensal firmarem contrato no âmbito do programa, dentre outras alterações que serão tratadas na sequência.

A primeira modalidade de financiamento estudantil aduzida pela Lei $\mathrm{n}^{0}$ 13.530, de 2017 é direcionada ao público mais necessitado, estudantes com renda familiar bruta de até três salários mínimos per capita, e oferece melhores condições de financiamento e uma série de outras melhorias na gestão e transparência do programa e para os alunos. Uma inovação trazida é a previsão de taxa de juros reais zero, enquanto a taxa de juros nominal fixada à época da publicação da norma era de $6,5 \%$ (BRASIL, 2017).

Além disso, respeitando a capacidade de pagamento do aluno, o prazo e a forma de pagamento das prestações do financiamento passa a ser mediante a vinculação do valor da prestação à renda efetiva do financiado. O prazo de pagamento quando da publicação da norma era de três vezes o período financiado, que na média indica prazo de amortização de doze anos, o qual se inicia somente após o final da carência e sem considerar qualquer proporção em relação à renda do devedor. O valor da prestação será calculado de maneira proporcional ao salário 
bruto do estudante financiado, mediante retenção diretamente na fonte pagadora e recolhimento direto ao Fies, portanto o período de amortização dependerá da renda do aluno - medida que constitui importante mecanismo de mitigação da inadimplência. Aliada a essas medidas, o agente financeiro, de acordo com as diretrizes do MEC e do Comitê Gestor do Fies - CG Fies, poderá pactuar medidas de estímulo à liquidação ou reescalonamento das dívidas vencidas, visando a assegurar o retorno dos capitais emprestados.

A Lei no 13.530 (BRASIL, 2017b) trouxe também a criação de uma segunda modalidade, mais ampla que o FIES, constituída parcialmente por recursos públicos e operacionalizada por instituições financeiras autorizadas a funcionar pelo Banco Central do Brasil, sejam elas públicas ou privadas, que assumirão integralmente o risco de crédito das operações e o custo de captação (Taxa de Longo Prazo - TLP) e pode atender, na forma da regulamentação, estudantes com renda bruta familiar mensal de até cinco salários mínimos per capita, contando com garantia exclusivamente privada, não abrangida pela cobertura oferecida pelo Fundo Garantidor - FG-FIES ou pelo FGEDUC.

A nova modalidade, o Programa de Financiamento Estudantil - P-Fies, garante também o menor valor de mensalidade ofertada pela instituição de ensino para os estudantes do Fies e a previsibilidade do valor total contratado no financiamento, inclusive com a definição do índice de reajuste a ser utilizado, proporcionando maior transparência ao processo.

As alterações relacionadas ao Fundo de Financiamento do Centro-Oeste FDCO, ao Fundo de Desenvolvimento do Nordeste - FNE e ao Fundo de Desenvolvimento da Amazônia - FDA, de que tratam a Lei Complementar no 129, de 2009, a Medida Provisória no 2.156-5 e a Medida Provisória no 2.157-5, ambas de 2001, têm por objetivo permitir que recursos desses Fundos possam ser direcionados para o financiamento a estudantes regularmente matriculados em cursos superiores não gratuitos nas respectivas regiões de atuação.

Há ainda a possibilidade de uso de linha de crédito do Banco Nacional de Desenvolvimento Econômico e Social - BNDES para financiamento do P-Fies, em que as instituições financeiras assumem totalmente o risco de crédito. Isso ampliará a contribuição do BNDES como fomentador do desenvolvimento econômico do país, 
em consonância com o previsto no § 10 do art. 239 da Constituição Federal de 1988 (BRASIL, 2009). Assim como os recursos dos fundos regionais, este também será operacionalizado pelas instituições financeiras autorizadas, as quais assumirão o risco integral da operação.

No contexto das alterações voltadas à sustentabilidade do FIES, está a eliminação da fase de carência do financiamento, período compreendido entre a fase na qual o estudante está frequentando a graduação e a fase de amortização, quando o estudante começa a pagar as prestações do empréstimo. Como o estudante já efetua durante o curso o pagamento às instituições de ensino da parcela da mensalidade não financiada pelo programa, o objetivo da medida é que o aluno mantenha a disciplina de pagamentos imediatamente após a conclusão do curso. Adicionalmente, a medida contribui para que os recursos emprestados comecem a retornar ao Fundo mais cedo, pois o prazo de carência quando da publicação da Medida Provisória era de dezoito meses.

Durante o período do curso, fase de utilização do financiamento estudantil, como forma de estimular o efetivo acompanhamento da evolução dos preços praticados pelas instituições de ensino, os estudantes pagarão diretamente ao agente financeiro o valor correspondente à parcela das mensalidades não financiadas (coparticipação). Em substituição ao pagamento trimestral de juros de até $R \$$ 150,00, praticado até a publicação da Medida Provisória, o estudante irá efetuar o pagamento do valor equivalente às despesas operacionais do agente financeiro e de seguro prestamista para cobertura da totalidade do contrato.

Também será criado um novo Fundo Garantidor do Fies- FG-Fies, que terá integralização inicial da União e participação das entidades mantenedoras, que serão cotistas do Fundo na proporção inicial de $13 \%$ sobre o valor dos encargos educacionais financiados, percentual que irá variar a partir do segundo ano de criação, de acordo com a inadimplência dos estudantes que cursaram cada instituição de ensino, como medida de incentivo à qualidade dos cursos, com reflexo na empregabilidade dos formandos.

O FG-Fies tem por objetivo a complementariedade de renda dentro do prazo de amortização e a garantia do risco de crédito dos financiamentos. Os estudantes com renda familiar mensal bruta per capita de até um salário-mínimo e meio têm a 
cobertura exclusiva do Fundo Garantidor e os estudantes com renda superior precisarão indicar fiador.

O aumento do incentivo à participação no risco de crédito por parte das instituições de ensino potencializa os efeitos da política de inserção social promovida pela educação ao facilitar o acesso dos estudantes de menor renda aos cursos de nível superior e auxiliará no desenvolvimento de uma mão de obra qualificada, cada vez mais necessária para obtenção de um crescimento sustentável de médio e longo prazos, visto que haverá a certeza de retorno dos capitais investidos pelo FIES, pois eventuais perdas serão assumidas exclusivamente pelo FG-Fies.

O Prouni que foi instituído por meio da Medida Provisória 176 de 13/09/04, regulamentado pelo decreto no 5.245 de 15/10/04 e institucionalizado pela Lei $n^{\circ}$ 11.096, de 13 de janeiro de 2005 (BRASIL, 2005), é um programa do Ministério da Educação, criado pelo Governo Federal, que oferece bolsas de estudos em instituições de educação superior privadas, em cursos de graduação e sequenciais de formação específica a estudantes brasileiros sem diploma de nível superior.

As instituições de ensino que participam do Prouni ficam isentas de uma série de impostos e incentivos fiscais, dentre eles: o Imposto de Renda da Pessoa Jurídica, Contribuição Social sobre o Lucro Líquido, Contribuição Social para Financiamento da Seguridade Social e Contribuição para o Programa de Integração Social.

As bolsas podem ser integrais ou parciais. As integrais são oferecidas para estudantes que possuam renda familiar, por pessoa, de até um salário mínimo e meio, e a parcial que é de $50 \%$ para estudantes que possuam renda familiar, por pessoa, de até três salários mínimos.

Só é possível se candidatar a bolsa do Prouni os estudantes que se submeterem ao Exame Nacional do Ensino Médio (ENEM) e obtido a nota mínima de 400 pontos na média das cinco notas obtidas nas provas do Exame. Os resultados do ENEM são usados como critério para a distribuição das bolsas de estudos, isto é, as bolsas são distribuídas conforme as notas obtidas pelos estudantes no ENEM.

Ainda, os alunos que possuírem bolsa de $50 \%$ poderão financiar o restante através do Fies, isso reflete uma medida do Governo de unificação do Prouni e do Fies com o intuito de possibilitar um maior acesso dos estudantes ao ensino superior. 
Percebe-se que desde a sua implantação em 2005 o número de bolsas ofertadas pelo Prouni passou de 112.275 (cento e doze mil duzentos e setenta e cinco) para 306.726 (trezentos e seis mil, setecentos e vinte seis), conforme dados extraídos do gráfico abaixo disponíveis no site do Prouni através do SisProuni com dados que vão de 2005 a 2014.

\section{Gráfico 1 - Número de Bolsas ofertadas pelo Prouni de 2005 a 2014}

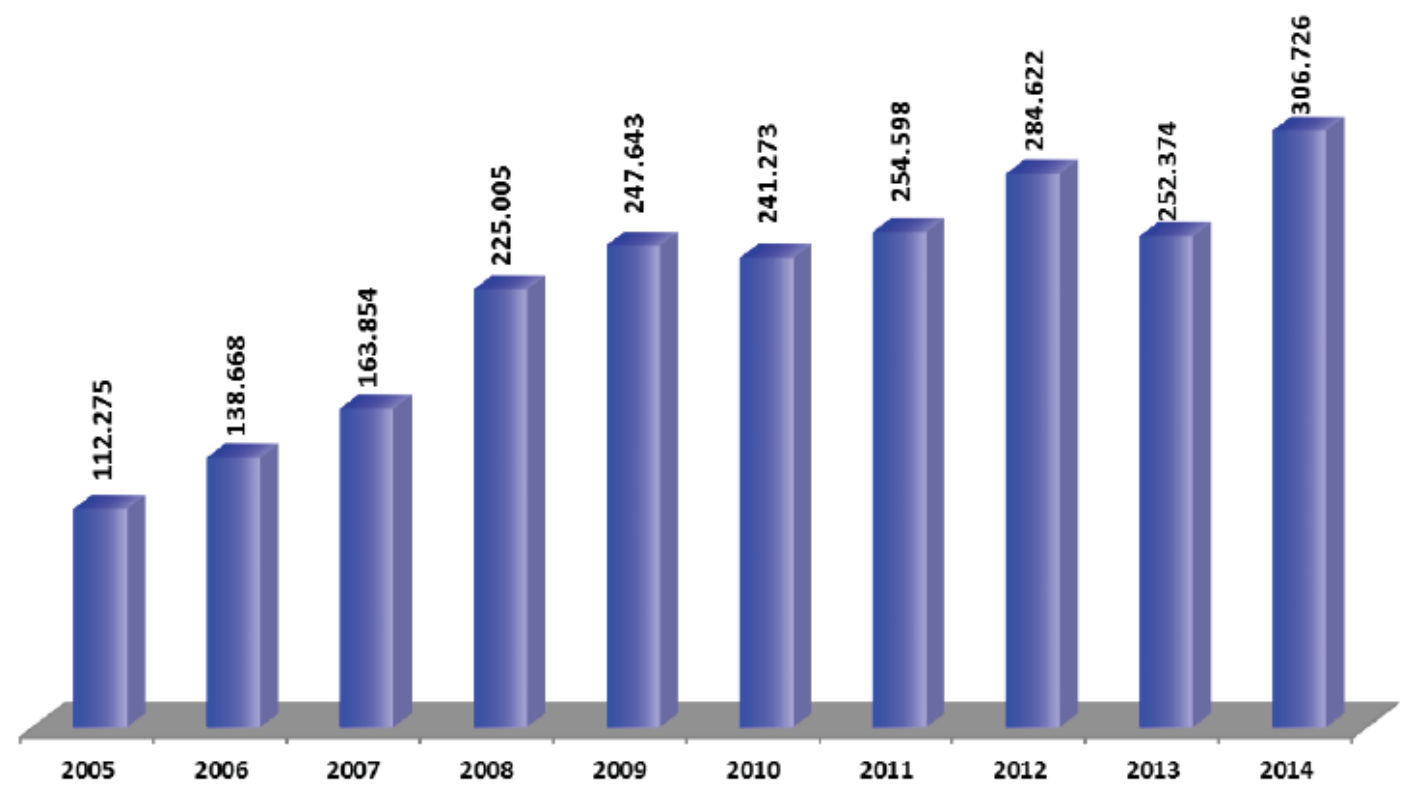

Fonte: SisProuni (BRASIL, 2016b).

Tais números possibilitam afirmar que a política pública do Programa Universidade para todos tem se mostrado desde a sua criação um instrumento de democratização do ensino, pois, possibilitou as pessoas de baixa renda, que até então não tinham qualquer tipo de perspectiva de acesso ao ensino superior, frequentar as instituições particulares usufruindo de bolsas de $100 \%$ ou $50 \%$.

As mudanças recentes que possibilitaram uma unificação das políticas públicas FIES e Prouni estão em consonância com o papel que o Estado deve desenvolver, que é de implementar políticas públicas que visem uma maior efetivação dos direitos fundamentais, dentre eles o direito a educação, pois é somente através da educação que é possível o crescimento em todos os sentidos, mas principalmente econômico e social. 


\section{CONSIDERAÇÕES FINAIS}

Tendo em vista os aspectos observados, pode-se afirmar que o tema das políticas públicas tem despertado muito a atenção dos estudiosos do direito, que se mostram preocupados não só com o estudo da legislação, bem como dos direitos concedidos aos cidadãos, mas também com a forma que esses direitos serão assegurados pelo Estado.

Sendo assim, num primeiro momento constata-se que o direito à educação constitui-se em direito social fundamental, o qual está consagrado na Constituição Federal, bem como que o Estado tem o dever de garantir aos cidadãos os direitos considerados como o mínimo existencial, os quais compõem o princípio maior do Estado Democrático de Direito: a dignidade da pessoa humana.

Assim, o direito a uma vida digna só é possibilitado aos cidadãos através da garantia de acesso aos direitos fundamentais, que representam os direitos imprescindíveis à subsistência humana, dentre eles o direito à educação.

Como sabe-se cabe ao Estado garantir e possibilitar o acesso aos direitos fundamentais consubstanciados na Carta Magna, nesse contexto, as políticas públicas desempenham um papel fundamental, pois é através da implementação delas que o Estado possibilita que os cidadãos tenham uma maior efetivação dos seus direitos fundamentais.

Desse modo, as políticas públicas devem consistir em uma ação governamental que vise efetivamente atender as demandas da sociedade, sob pena de se tornar inócua, por não estar ligada a consecução dos fins do Estado.

Dentre as políticas públicas, destacam-se as educacionais, mais especificamente o Programa Universidade Para Todos - Prouni e o Fundo de Financiamento ao Estudante do Ensino Superior - Fies, que se constituem em políticas públicas destinadas a permitir a população de baixa renda acesso ao ensino superior em instituições de ensino privado, seja por meio de bolsas ou financiamento.

Diante de uma análise dessas políticas, percebe-se que as últimas alterações implementadas no FIES possibilitaram um aumento expressivo no número de estudantes beneficiados pelo financiamento, isso se deve ao fato de que inúmeros 
entraves e restrições foram abolidos, ao passo que os benefícios foram ampliados, com o advento da Lei $n^{0}$. 12.202/10, o que permitiu um maior acesso ao ensino superior, já que mais pessoas podem ser beneficiadas pelo programa.

O mesmo pode-se perceber em relação ao Prouni que nos últimos anos aumentou o número de bolsas concedidas de forma significativa.

Não resta dúvida que, na medida do possível, o Estado tem possibilitado o acesso a educação, uma vez que tem implementado políticas públicas educacionais visando esse fim e tais políticas de fato estão possibilitando um maior acesso ao ensino superior.

Assim, as políticas públicas educacionais FIES e Prouni se mostram como instrumentos de democratização do ensino superior a medida em que viabilizam a uma parcela da população, por muito tempo excluída, o acesso a educação que Ihes permita uma inserção no mundo social e econômico.

\section{REFERÊNCIAS}

AZEVEDO, Janete M. Lins de. A educação como política pública: polêmicas do nosso tempo. Campinas, SP: Autores Associados, 2001.

AZEVEDO, Sérgio de. Políticas públicas: discutindo modelos e alguns problemas de implementação. In: SANTOS JÚNIOR, Orlando A. et al. (org.). Políticas públicas e gestão local: programa interdisciplinar de capacitação de conselheiros municipais. Rio de Janeiro: Fase, 2003. p. 38-44.

BOBBIO, Norberto. Teoria geral da política: a filosofia política e as lições dos clássicos. Rio de Janeiro: Campus, 2000.

BONETI, Lindomar Wessler. Políticas públicas por dentro. Ijuí: Ed. Unijuí, 2006.

BONTEMPO, Alessandra Gotti. Direitos sociais: eficácia e racionabilidade à luz da Constituição de 1988. Curitiba: Juruá, 2005.

BRASIL. Constituição (1988). Constituição da República Federativa do Brasil. Brasília, DF: Senado Federal, 2009.

BRASIL. Lei $\mathbf{n}^{\circ}$ 11.096, de 13 de janeiro de 2005. Institui o Programa Universidade para Todos - PROUNI, regula a atuação de entidades beneficentes de assistência social no ensino superior; altera a Lei no 10.891, de 9 de julho de 2004, e dá outras providências. Brasília, DF: Presidência da República, 1 de dezembro de 
2016. Disponível em: http://www.planalto.gov.br/ccivil_03/_Ato20042006/2005/Lei/L11096.htm. Acesso em: 1 dez. 2018.

BRASIL. Lei n⿳0 12.202, de 14 de janeiro de 2010. Altera a Lei no 10.260, de 12 de julho de 2001, que dispõe sobre o Fundo de Financiamento ao Estudante do Ensino Superior - FIES (permite abatimento de saldo devedor do FIES aos profissionais do magistério público e médicos dos programas de saúde da família; utilização de débitos com o INSS como crédito do FIES pelas instituições de ensino; e dá outras providências).

BRASIL. Lei n⿳0 $\mathbf{1 3 . 3 6 6}$, de 1 de dezembro de 2016. Altera as Leis n os 10.260 , de 12 de julho de 2001, que "dispõe sobre o Fundo de Financiamento ao estudante do Ensino Superior e dá outras providências", para atribuir às instituições de ensino responsabilidade parcial pela remuneração dos agentes operadores do Fundo, e 9.394, de 20 de dezembro de 1996, que "estabelece as diretrizes e bases da educação nacional", para vedar a concessão de tutela antecipada que tenha por objeto a autorização para o funcionamento de curso de graduação por instituição de educação superior. Brasília, DF: Presidência da República, 1 de dezembro de 2016. Disponível em: http://www.planalto.gov.br/ccivil_03/_Ato20152018/2016/Lei/L13366.htm. Acesso em: 1 dez. 2018.

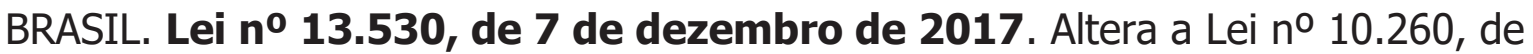
12 de julho de 2001, a Lei Complementar $n^{\circ} 129$, de 8 de janeiro de 2009, a Medida Provisória n⿳0 2.156-5, de 24 de agosto de 2001, a Medida Provisória n 2.157-5, de 24 de agosto de 2001, a Lei no 7.827, de 27 de setembro de 1989, a Lei no 9.394, de 20 de dezembro de 1996 (Lei de Diretrizes e Bases da Educação Nacional), a Lei no 8.958, de 20 de dezembro de 1994, a Lei no 9.766, de 18 de dezembro de 1998, a Lei no 8.745, de 9 de dezembro de 1993, a Lei no 12.101, de 27 de novembro de 2009, a Lei no 12.688, de 18 de julho de 2012, e a Lei no 12.871, de 22 de outubro de 2013; e dá outras providências. Brasília, DF: Presidência da República, 7 de dezembro de 2017b. Disponível em: http://www.planalto.gov.br/ccivil_03/_Ato20152018/2017/Lei/L13530.htm. Acesso em: 1 dez. 2018.

BRASIL, Ministério da Educação. Prestação de contas: relatório de auditoria anual de contas, 07 de julho de 2016. [S.I.]: MEC, 2016. Disponível em:

http://portal.mec.gov.br/index.php?option=com_content\&view=article\&id=242\&Item id =525. Acesso em: 1 dez. 2018.

BRASIL. Ministério da Educação. Processo de Contas Fies: relatório de gestão do FIES exercício 2017. [S.I.]: MEC, 2017a. Disponível em:

http://portal.mec.gov.br/index.php?Itemid=1064\&id=14949\&option=com_content\&v iew=article. Acesso em 1 de dezembro de 2018.

BRASIL. Ministério da Educação. Representações gráficas: dados e estatítiscas de bolsas ofertadas por ano. PROUNI, [s.l.], 27 jul. 2016b. Disponível em:

http://siteprouni.mec.gov.br/index.php?option=com_content\&view=article\&id=136:r epresentas-grcas\&catid=26:dados-e-estaticas\&Itemid=147. Acesso em: 1 dez. 2018. 
BUCCI, Maria Paula Dallari. Buscando um conceito de políticas públicas para a concretização dos direitos humanos. In: BUCCI, Maria Paula Dallari et al.

Direitos humanos e políticas públicas. São Paulo: Pólis, 2001. (Cadernos Pólis, 2). Disponível em: http://www.polis.org.br/uploads/831/831.pdf. Acesso em: 3 dez. 2018.

BUCCI, Maria Paula Dallari. Direito administrativo e políticas públicas. São Paulo: Saraiva, 2002.

HERINGER, Rosana Rodrigues. Estratégias de descentralização e políticas públicas. In: MUNIZ, José Norberto; GOMES, Elaine Cavalcante. Participação social e gestão pública: as armadilhas da política de descentralização. Belo Horizonte: Segrac Editora e Gráfica, 2002. p. 75-82. 